THE ANNALS OF "DUNĂREA DE JOS" UNIVERSITY OF GALATI

FASCICLE III, 2019, VOL. 42, NO.2, ISSN 2344-4738, ISSN-L 1221-454X

ELECTROTECHNICS, ELECTRONICS, AUTOMATIC CONTROL, INFORMATICS

Article DOI: https://doi.org/10.35219/eeaci.2019.2.06

\title{
OPTIMAL DESIGN OF THE ROTOR OF AXIAL FLUX RARE EARTH PERMANENT MAGNET SYNCHRONOUS MACHINE
}

\author{
Madalin Costin ${ }^{1,2}$, IonVoncila ${ }^{1}$, Ion Paraschiv ${ }^{1}$ \\ ${ }^{1}$ Faculty of Automatic Control, Computer Science, Electrical and Electronics Engineering, \\ „,Dunărea de Jos” University of Galati, Romania \\ 2"'Gheorghe Asachi" Technical University of Iasi-Romania, Faculty of Automatic Control and Computer \\ Science, Blvd. Mangeron, No. 59A, 700050, Iasi, Romania \\ e-mail: Madalin.Costin@ugal.ro
}

\begin{abstract}
This paper presents a solution for the optimal design of the rotor of axial flux rare earth permanent magnet machine by minimizing the volume of the permanent magnet. The objective of the optimization is to find the geometric dimensions that lead to a minimum value of the volume of the permanent magnet. The proposed solution uses the FEMM (Finite Element Method Magnetics) software package, and offer several significant benefits: high power density, larger range of frequency in operation, compactness, high torque capability.
\end{abstract}

Keywords: axial flux, permanent magnet, finite elements method, magnetic flux density, geometric dimensions

\section{INTRODUCTION}

In industrial and domestic applications, an important attention is accorded to servo drives system. Compared with classical machines, modern unconventional machines provide improved performances: high torque capability, large range of speed, robustness, stability etc. (see Boldea, 2005; Boldea, 2018).

An important requirement in many applications is to reduce the main geometric dimensions of the electric drives. This can be done by increasing the linear current density, while the magnetic saturation effect is avoided (Gavrila \& Centea, 1998). In this situation the domain of practical applications is largely extended: motion control, high tech servo mechanisms, electrical vehicles etc. (Pyrhonen et al., 2009).

In the order to meet the current requirements imposed by operation conditions, the axial flux synchronous machine presents certain benefits. The stator is spitted in two units, which leads to increasing the linear current density (Gieras, et al., 
2008; Gieras, et al., 2009). The rotor of the machine is built with a permanent magnet, which increases the global efficiency of machine and generates the possibility to create multipolar structure. Also, the dimensions of the rotor are substantially reduced.

The design of axial flux permanent magnet synchronous machine (AFPMSM) starts from the requirements of power (or electromagnetic torque), speed, and other additional requirements imposed by design theme (Gieras, et al., 2008).

The design of AFPMSM involves three levels: electromagnetic, thermal and mechanical computation. The electromagnetic and mechanical computations have the same structure as that of classical machine, while the heat transfer is different.

In the operation of an electrical machine the distribution of magnetic field is crucial for a proper operation. In these conditions, the computation of magnetic field is done by finite elements method (FEM), that allow an efficient representation of magnetic field based on a low computation effort.

The paper is organized as follows. In the second section is presented the formulation of problem solved in the paper. It is searched the optimal solution represented by the main geometrical dimensions that lead to a minimal value of volume of permanent magnet. The distribution of magnetic field is computed in the third section. Finally, the conclusion presents the main approach of the paper.

\section{PROBLEM FORMULATION}

We consider an AFPMSM depicted in fig. 1(Gieras, et al., 2008).

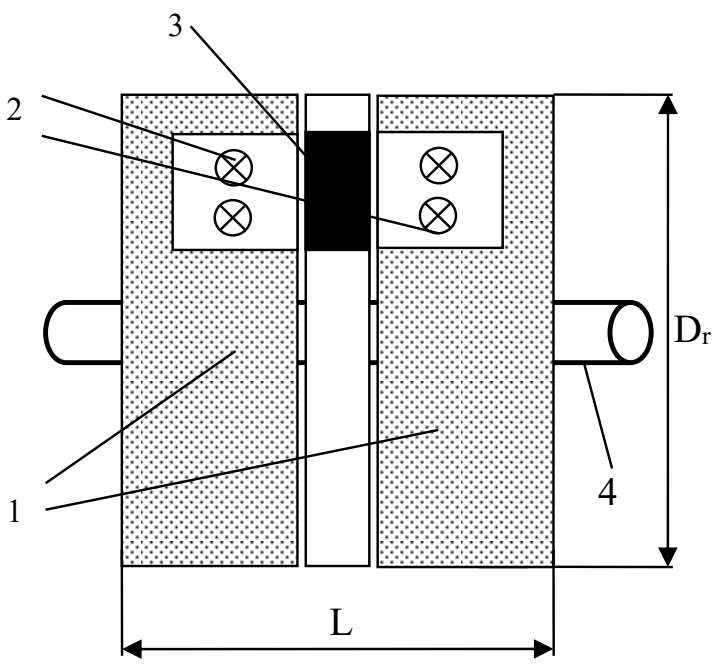

Fig.1. AFPMSM topology

The main elements are: 1 - stator magnetic core, 2 - stator magnetic windings, 3 - permanent magnet rotor and 4 - rotor shaft.

The design theme requirements are:

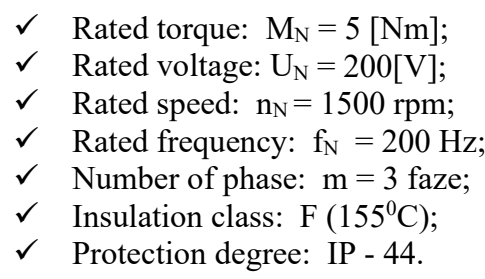

The rotor is design by using $\mathrm{NeFeB}$ permanent magnet of high performances. In fig. 2 are represented the demagnetization characteristics of permanent magnet.

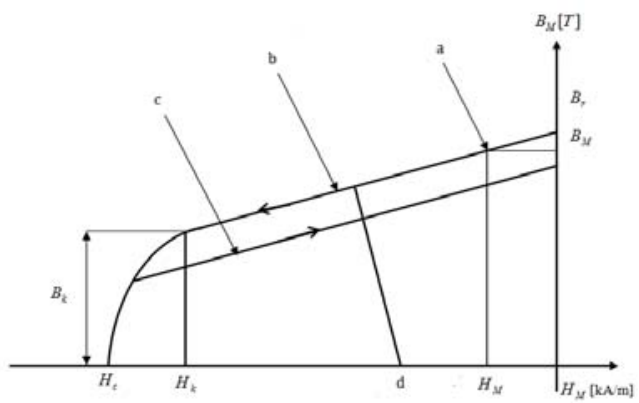

Fig.2. Demagnetization characteristics

The main curves highlighted are: a - operation in open circuit, b - main characteristic, c - reversal magnetic characteristic and $\mathrm{d}$ - demagnetization due to stator current. All involved quantities are presented in table 1 .

Table 1 The main features of $\mathrm{NeFeB}$ permanent magnet

\begin{tabular}{clcc}
\hline No. & \multicolumn{1}{c}{ Quantity } & M. U. & Value \\
\hline 1 & $\begin{array}{l}\text { Remanent } \\
\text { magnetic } \\
\text { density- } B_{r}\end{array}$ & $T$ & 1.2 \\
\hline 2 & $\begin{array}{l}\text { Coercive } \\
\text { field } H_{c}\end{array}$ & $\mathrm{kA} / \mathrm{m}$ & 1000 \\
\hline 3 & $(\mathrm{BH})_{\max }$ & $\mathrm{kJ} / \mathrm{m}^{3}$ & 250 \\
\hline 4 & $\begin{array}{l}\text { Relative } \\
\text { permeability } \mu_{r}\end{array}$ & - & 1.07 \\
\hline
\end{tabular}


THE ANNALS OF "DUNĂREA DE JOS" UNIVERSITY OF GALATI

FASCICLE III, 2019, VOL. 42, NO. 2, ISSN 2344-4738, ISSN-L 1221-454X

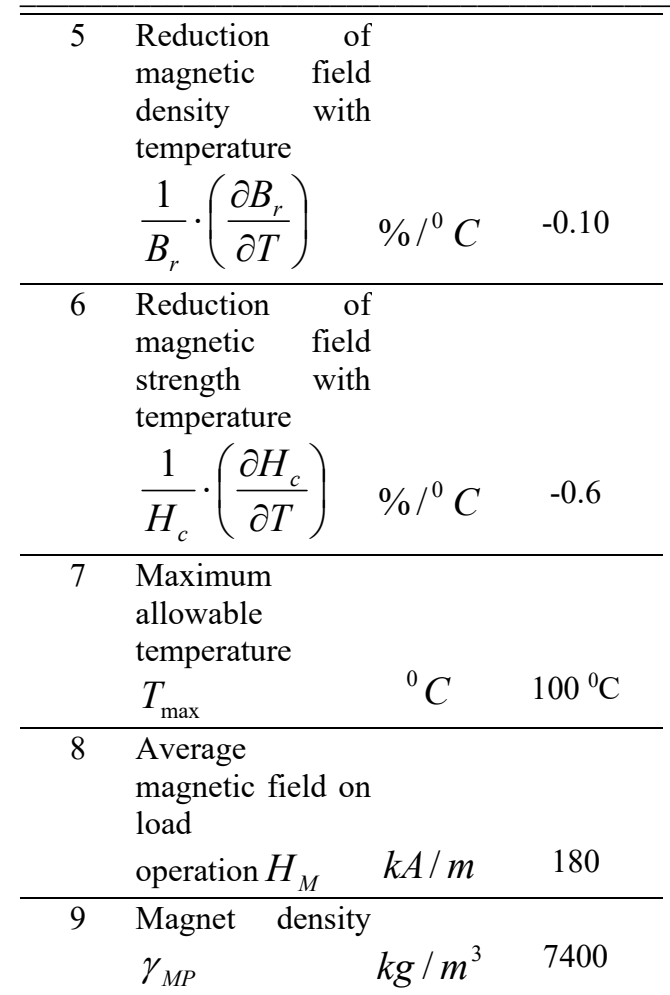

The optimization problem is definted by:

(1) find $\left(D_{r}, L, D_{e m}, D_{i m} \mathrm{~K}\right)$

until

(2)

$$
V_{m}=\min
$$

By using the gradient method optimization method from Matlab, we obtained the main geometric dimensions:

$$
\begin{array}{ll}
\checkmark & D_{r}=120[\mathrm{~mm}] ; \\
\checkmark & L=121.8[\mathrm{~mm}] ; \\
\checkmark & D_{e m}=108[\mathrm{~mm}] ;
\end{array}
$$

$$
\checkmark \quad D_{e m}=72[\mathrm{~mm}] .
$$

for an optimal permanent magnet volume:

$$
V_{\text {mopt }}=12,27 \cdot 10^{-6}[\mathrm{~mm}] .
$$

\section{MAGNETIC FIELD ANALYSIS}

Due to the geometric symmetry of AFPMSM, the simulation is performed on a superior half. In Fig. 3 is presented the geometric structure considerated.

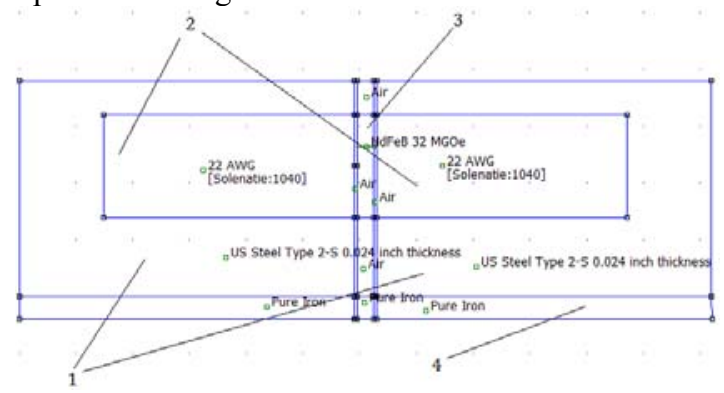

Fig.3. The domain analysis by FEMM ${ }^{\circledR}$

The main elements depicted on the figure are:

$\checkmark \quad 1$ - stator magnetic core;

$\checkmark \quad 2$ - stator magnetic windings;

$\checkmark \quad 3$ - permanent magnet rotor;

$\checkmark \quad 4$ - rotor shaft.

The simulations were performed in FEMM $\left({ }^{\circ}\right.$ software (Baltzis, 2008), by tacking into account the next boundaries conditions:

(1) $\quad \bar{A} \mid=0 \quad$ on the outside boundaries,

$$
\frac{\partial \bar{A}}{\partial \bar{n}} \mid=0 \text { in rest. }
$$

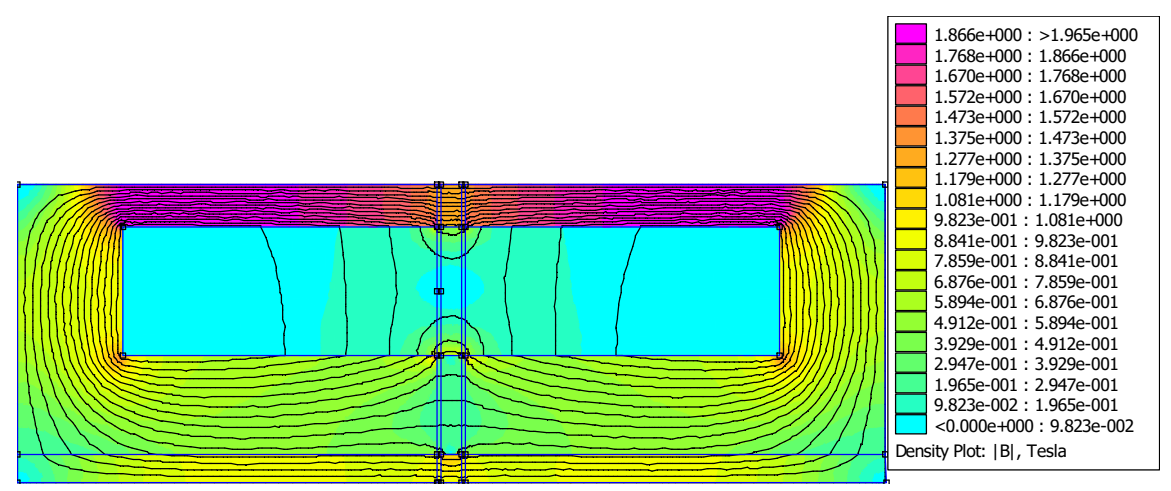


Fig.4. Mapping of magnetic flux density

In fig. 4 is represented the map of magnetic flux density.

For our analysis it is relevant to perform the magnetic field distribution in front of the permanent magnet, in the order to visualize the utile component of field.

In fig. 5 and fig. 6 are represented the normal and tangential components of magnetic flux density.

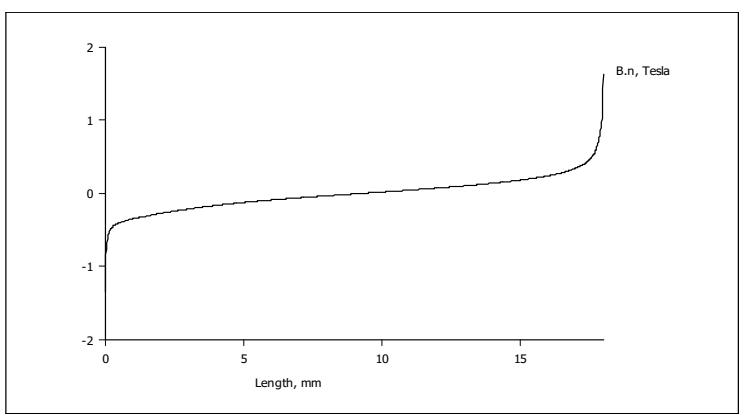

Fig.5. Normal component of magnetic flux density

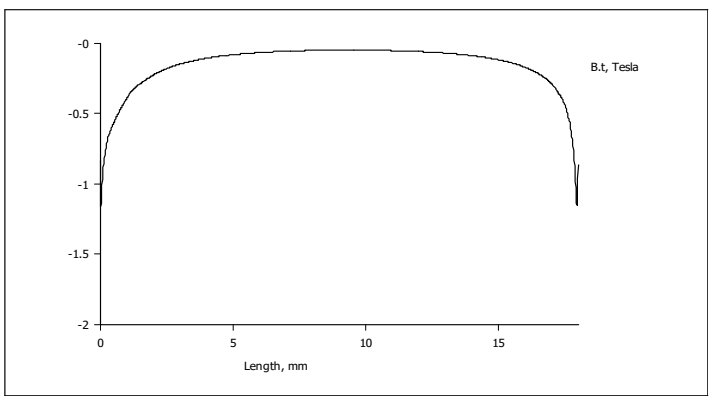

Fig.6. Tangential component of magnetic flux density

It can be concluded that the distribution of magnetic field is performed according to the influences of the magnetic permeability.

Finally, in fig. 7 and fig. 8 are depicted the components of magnetic strenght.

Similary conclusions may be apreciated from the qualitative curves.

As a general conclusion, the magnetic field is welldistributed in the order to maintain a high value of electromagnetic torque and a low dispersion (see also Virtič et al, 2015).

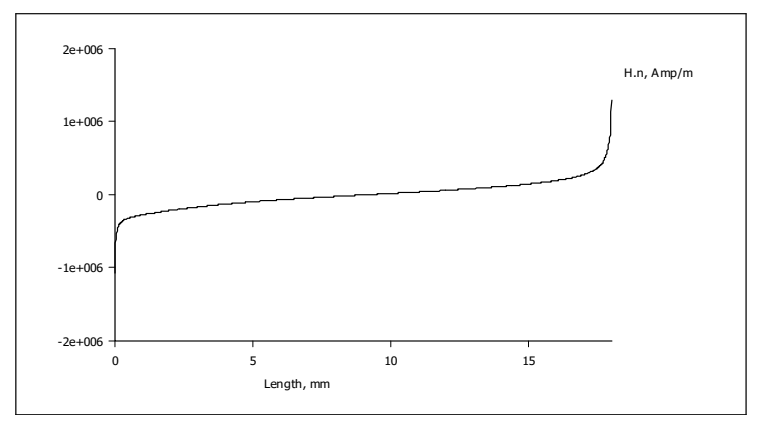

Fig.7. Normal component of magnetic flux strength

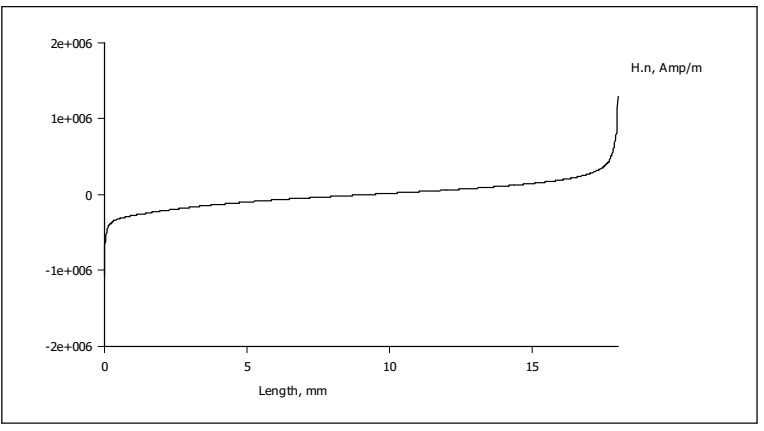

Fig.8. Tangential component of magnetic flux strength

\section{CONCLUSIONS}

Axial flux synchronous machines excited with permanents magnets become an important solution for high performances drives.

The topology developed in the paper has some significant benefits: high power density, large range operation of frequency, compactness, high torque capability.

From the design performed in the paper it can be concluded that the distribution of magnetic field is essential for a proper operation. The key objective of the study described in this paper is to find the main geometric dimensions that lead to minimal value of the volume of permanent magnet.

Future work involves the research for optimal design of a modified machine topology highlighting the field distribution, which is fundamental for a safe operation. 


\section{REFERENCES}

Baltzis, K. B. (2008). The FEMM Package: A Simple, Fast, and Accurate Open Source Electromagnetic Tool in Science and Engineering. Journal of Engineering Science \& Technology Review, 1(1).

Boldea, I., (2018) The induction Machines Design Handbook, second edition, CRC Press Publishing House.

Boldea, I. (2005). Variabile Speed Generators, CRC Press Publishing House.

Gavrila, H. and Centea O. (1998). Modern Theory of Electromagnetic Field and Aplications, ALL Publishing House, Bucharest. (In Romanian)
Gieras, Jacek F., Rong-Jie Wang, and Maarten J. Kamper. Axial flux permanent magnet brushless machines. Springer Science \& Business Media, 2008.

Gieras, Jacek F. (2009). Permanent magnet motor technology: design and applications. CRC press, 2009.

Pyrhonen, J., Jokinen, T., and Harabovcova, V., (2009) Design of Rotating Electrical Machines, John Wiley and sons.

Virtič, P., Vražić, M., \& Papa, G. (2015). Design of an axial flux permanent magnet synchronous machine using analytical method and evolutionary optimization. IEEE Transactions on Energy Conversion, 31(1), 150-158. 